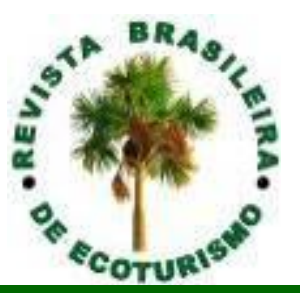

\title{
Estudo preliminar da percepção do meio aquático marinho com mergulhadores recreativos no litoral potiguar
}

\section{Preliminary study of the perception of the marine aquatic environment with recreational divers in the Potiguar coast}

Diego Vitor Filgueira-da-Silva, Ana Beatriz Gomes-Ferreira, Sueli Aparecida Moreira

RESUMO: Realizou-se o presente estudo com o objetivo de identificar a percepção ambiental de mergulhadores autônomos sobre os impactos do mergulho na ecologia marinha. Portanto, desenvolveu-se estudo de natureza qualitativa cujos dados foram obtidos através de roteiro de entrevista com 10 mergulhadores com certificação PADI que atuam em Maracajaú e Natal, no litoral do Rio Grande do Norte (Brasil). As percepções foram categorizadas conforme a proposta de análise temática de Bardin (1979). Em conclusão, a percepção dos mergulhadores revelou que a preservação do meio marinho demanda ações governamentais urgentes. O mergulho recreativo deve ser controlado sob a perspectiva do turismo ecológico sustentável. A Educação Ambiental deve ser prioritária e contínua.

PALAVRAS-CHAVE: Turismo Ecológico; Educação Ambiental; Turismo Subaquático; Ecossistema Marinho.

\section{ABSTRACT}

The present study was carried out with the objective of identifying the environmental perception of scuba divers on the impacts of diving on marine ecology. Thus, the qualitative study was developed with data collected from scripted interviews with 10 PADI certified divers who work in Maracajaú and Natal, on the coast of Rio Grande do Norte (Brazil). The perceptions were categorized according to the thematic analysis proposed by Bardin (1979). In conclusion, the divers' perception revealed that the preservation of the marine environment requires urgent government action. Recreational diving must be controlled from the perspective of sustainable ecological tourism. Environmental education must be a priority and continuous.

KEYWORDS: Ecological Tourism; Environmental Education; Underwater Tourism; Marine Ecosystem. 


\section{Introdução}

Mergulho é a observação, contemplação e fruição de ambientes submersos, com ou sem a utilização de equipamentos especiais (MTur, 2008). O primeiro registro de mergulho remete-se à Grécia Antiga e data de 480 a.C., quando o historiador grego Pausâncio narrou a proeza de Scyllis, um nadador experiente e instrutor de mergulho. Ele ensinou à filha Hydna a mergulhar profundamente e a nadar longas distâncias. Essas habilidades foram cruciais para deter o avanço dos persas pelo continente grego. A marinha persa havia saqueado Atenas e vencido a batalha de Termópilas e, enquanto se dirigia à Salamina, pai e filha nadaram dez mil milhas em mar aberto durante uma tempestade e mergulharam para cortar as amarras das embarcações persas, encalhando-as (MARK, 2014).

Atribui-se à Grécia antiga o uso do primeiro respirador da história do mergulho, que consistia de um cano de junco, um tipo de madeira oca, que pode ter inspirado a invenção do atual snorkel. Esse tipo de respirador, em material sintético, permite mergulhar superficialmente no mar. $\mathrm{O}$ mergulho livre em apneia é uma prática comum para turistas inexperientes utilizandose respirador (snorkel), pé de pato e colete salva-vidas com o objetivo de observar a fauna e flora aquática. Enquanto o mergulho autônomo pode ser realizado no mar, rios, lagos ou cavernas apropriadas para ecoturistas mais experientes, pois necessita de curso especializado e com certificação para a utilização de equipamento autônomo de respiração (cilindro de ar comprimido), que permite submergir a maiores profundidades, onde a biodiversidade se expande (BUENO et al, 2011).

O mergulho recreativo foi popularmente difundido na Arábia, em decorrência das operações militares e da prática de salvamento centrada nos portos de maior movimento comercial do Mediterrâneo oriental. Desde o século I a. C., as operações estavam tão organizadas que foi estabelecida uma escala de pagamentos para trabalhos de salvamento, baseada no esforço e no risco na profundidade (ROWE; SANTOS, 2016).

Contudo, a mudança mais significativa aconteceu quando o militar, oceanógrafo e explorador Jacques-Yves Cousteau e o engenheiro Emile Gagnan aprimoraram o Aqualung, um equipamento de mergulho SCUBA, que consiste num cilindro portátil de ar comprimido e um regulador de mergulho, possibilitando ao mergulhador suprir a necessidade de gás respirável à pressão ambiente. Somente no ano de 1946, esse sistema de circuito aberto de ar comprimido, conhecido como Aqua-Lung, passou a ser comercializado (HALLS; KRESTOVNIKOFF, 2006).

A prática do mergulho subaquático tornou-se acessível ao público em geral motivada pela mídia, principalmente pela divulgação promovida por Jacques Cousteau, cuja participação resultou em mais de 100 filmes com imagens de mergulhos que tiveram grande repercussão mundial. Rowe e Santos (2016), em estudo sobre mergulho, constataram que a principal motivação à iniciação da prática era devido às notícias, reportagens e filmes.

No Brasil, o mergulho recreativo em virtude da atividade turística vem impactando de modo negativo o ambiente marinho. Verificou-se que 0 
pisoteio de corais é uma das ações que causa danos, muitas vezes, irreversíveis ao ecossistema marinho (SILVA; GHILARDI-LOPES, 2012). O turismo subaquático, também causa sérios impactos nos costões rochosos (BROTTO et al., 2012).

Os impactos ambientais do turismo subaquático podem ocorrer de duas formas: utilizando barcos para o deslocamento até o local de mergulho - despejando óleo e diesel pelos motores no mar - e pelo comportamento do mergulhador submerso. Aqueles menos experientes causam os maiores impactos, visto que não conseguem controlar sua flutuação, podendo quebrar os corais com suas nadadeiras (BUENO et al;; 2011; PEDRINI, 2011).

Além dos impactos negativos devido à quebra dos corais, estudo realizado em Maracajaú por Silva, Fujii e Marinho-Soriano (2012), notou que a abundância de algas marinhas era susceptível à intensidade de fluxo turístico. Enquanto no local de maior atividade turística havia menor diversidade de espécies, no de menor frequência de turistas havia uma diversidade maior de algas. Os resultados evidenciaram o impacto negativo do turismo sobre as algas marinhas e, consequentemente sobre os recifes de corais.

Definições relativas à prática de mergulho recreativo têm sido atreladas ao ecoturismo e ao turismo de aventura (QUEIROZ-NETO, 2012). Sob esta perspectiva, Augustowski e Francine publicaram a "Carta de Anchieta" em 2002, após sua apresentação em evento ocorrido no Parque Estadual da Ilha Anchieta, em São Paulo, envolvendo setores governamentais, não-governamentais e iniciativa privada (AUGUSTOWSKI; FRANCINE Jr, 2002).

A carta foi criada com a intenção de colaborar com o processo de valorização das áreas marinhas e das águas continentais. Portanto, ela classificou o mergulho recreativo, turístico e de lazer (RTL) e definiu diretrizes para a prática em Unidades de Conservação (UC). Distinguiu, também, os diferentes tipos de locais para a prática de mergulho recreativo: águas interiores (cavernas; rio, lagos e represas) e ambientes marinhos (recifes; costões rochosos; fundos não consolidados e recifes artificiais). Também apontou as diferentes modalidades de mergulho recreativo, turístico e de lazer, divididos em mergulho livre (snorkelling; apneia; pesca ou caça submarina e motorizada - mergulho a reboque) e autônomo (foto/vídeo; contemplativo - guiado ou não guiado); eventos sub; motorizado; treinamento (cursos incluindo batismo e avançado); não recreativo turístico ou de lazer (mergulho científico; profissional ou técnico) conferiu QueirozNeto (2012).

O ecoturismo é um modo especial de aprender pelo contato com a natureza e através de experiências práticas. O ecoturismo pode ser um modo de beneficiar a natureza, o visitante e a comunidade humana local, além de ser uma opção efetiva de sensibilizar sobre a importância de se preservar a geobiodiversidade (PEDRINI et al., 2010). Além de proporcionar o contato da coletividade humana com espaços naturais, o ecoturismo se propõe a assegurar sustentabilidade econômica e ecológica (MENDONÇA; 
NEIMAN, 2002). Em síntese, o ecoturismo assenta-se no tripé: interpretação, conservação e sustentabilidade (MTur, 2008).

No entanto, o ecoturismo marinho é praticamente inexistente a despeito da imensa zona costeira (PEDRINI, 2010). Ocorre um desconhecimento generalizado sobre turismo aquático no Brasil (ROWEL; SANTOS, 2016). O tradicional turismo marinho brasileiro tem sido altamente prejudicial nas suas mais variadas formas, como o mergulho recreacional. Suas atividades vêm gerando sérios impactos negativos (AUGUSTOWSKI; FRANCINE Jr, 2002).

Em áreas protegidas, o ecoturismo surge como única possibilidade de turismo não predatório. No entanto, as UCs têm sido criadas rotineiramente, no Brasil, sem que tenham condições de funcionar como unidades marinhas e costeiras. Para se realizar o ecoturismo costeiro e marinho é necessário que se disponibilize o conhecimento sobre geobiodiversidade, estabeleça trilhas marinhas, com investimentos na área de Educação Ambiental (EA) no mar (PEDRINI, 2010; 2011).

No seculo XXI, um ambiente de mergulho é economicamente importante para destinos turísticos, pois reflete avanços tecnológicos, envolve abordagens de gerenciamento multifacetadas e tem relevância nas discussões sobre mudanças climáticas e sustentabilidade ambiental (MUSA, G.; DIMMOCK, 2012). Considerando a Educação Ambiental (EA) como o mais importante atributo para instrumentalizar o turismo marítimo, realizouse 0 presente estudo com o objetivo de identificar a percepção de mergulhadores autônomos sobre turismo no meio aquático e seus efeitos sobre o meio marinho no litoral potiguar.

\section{Método}

A área de estudo compreende a comunidade de Maracajaú, localizada no município de Maxaranguape (litoral norte) e em Natal, ambos no Rio Grande do Norte. Durante a coleta de dados foi usado um aplicativo de gravador de voz do smartphone e cada entrevista durou em média 20 minutos, que foram feitas com 7 mergulhadores da operadora Parrachos Praia Clube (Maracajaú), 2 da operadora Portal de Maracajaú (Maracajaú) e 1 da Caju Divers (Natal).

O presente estudo é de natureza qualitativa e contou com a aplicação de um roteiro semiestruturado para guiar a coleta de dados. Os instrumentos foram aplicados com 10 mergulhadores durante o período de 20 de outubro a 10 de novembro de que 2017. O grupo de entrevistados era composto por 10 brasileiros, 8 nativos e 2 naturalizados, mergulhadores autônomos, idade entre 27 e 45 anos, residentes nos municípios de Maxaranguape e Natal. Apenas dois possuem ensino superior completo.

Em relação aos aspectos éticos de pesquisa com seres humanos, antes da entrevista os participantes eram convidados à leitura do Termo de Consentimento Livre e Esclarecido (TCLE), conforme Resolução CNS no 510/2016 do Ministério da Saúde, informando sobre o uso dos dados 
somente para fins científicos. Para garantir o anonimato, os nomes dos mergulhadores foram substituídos por nomes fictícios.

Para análise dos dados, os depoimentos foram percorridos em busca de categorias que demonstrassem a percepção ambiental por parte dos mergulhadores.

Ao prosseguir notou-se que na terminologia percepção ambiental está contida a ideia de sensação. Cada sensação é independente das outras e cabe à percepção unificá-las e organizá-las numa síntese (CHAUÍ, 2000). Sensação e percepção estão contidas no sujeito do conhecimento e o exterior é apenas a ocasião para que tenhamos a sensação ou percepção. Nesse caso, perceber depende da capacidade do sujeito de extrair a coisa externa (as sensações), organizar e interpretar (percepção). A percepção para os pesquisadores envolve decifrar padrões de uma variedade de informações sensoriais. Portanto, o caminho da sensação para a percepção depende do sujeito do conhecimento, que imprime sensações e dá organização e sentido a elas (CHAUí, 2000).

Enquanto as sensações são estímulos apreendidos pela visão, olfato, audição, paladar, toque, equilíbrio e dor, a percepção atribui significado e interpreta as informações sensoriais a fim de compreender o que acontece ao redor (DAVIDOFF, 1983; ROBBINS, 2002).

A percepção é a interpretação do meio ambiente de modo individualizado, subjetivo e influenciado por valores culturais. Além das experiências passadas e da aprendizagem, vários outros fatores individuais influenciam a percepção, que também é influenciada por nossa maneira individual de nos relacionarmos com o ambiente que nos cerca e por nossa cultura, valores, motivação, personalidade e estilo cognitivo (MORRIS; MAISTON, 2004, p. 121).

Então, optou-se pelo emprego da análise temática com o propósito de "descobrir os núcleos de sentido que compõem a comunicação e cuja presença, ou frequência no discurso pode significar ou reiterar alguma categoria do objetivo analítico escolhido" (BARDIN, 1979, p.105).

\section{Resultados e Discussão}

\section{Perfil sociodemográfico dos entrevistados}

Dos 10 entrevistados, 9 são do sexo masculino e 1 é do sexo feminino; com idade entre 26 e 45 anos; a maioria reside no município de Maracajaú, comunidade costeira do município de Maxaranguape. Realizam as atividades como mergulhadores autônomos há mais de 5 anos, com periodicidade mensal.

Em relação à formação acadêmica e treinamentos, 2 dos entrevistados concluíram o ensino fundamental, 6 concluíram o ensino médio e 2 completaram o ensino superior. Referente ao treinamento específico para o mergulho, 7 dos entrevistados possuem somente o curso básico, e 3 afirmaram ter feito o curso avançado (dive master). 


\section{Mergulho na percepção dos entrevistados}

$\mathrm{Na}$ percepção dos entrevistados notou-se que diferentes significados foram atribuídos à prática de mergulho, conforme quadro abaixo:

Quadro 1: Significados atribuídos à prática de mergulho recreativo, RN/2017.

Table 1: Meanings attributed to recreational diving practice, RN/Brazil, 2017.

\begin{tabular}{|c|c|}
\hline Mergulho como lazer & $\begin{array}{l}\text { "Para mim é coisa de relaxamento. É outro mundo lá embaixo... } \\
\text { É natureza... É importante você preservar também" (Rodolfo, } 27 \\
\text { anos). }\end{array}$ \\
\hline Mergulho como trabalho & $\begin{array}{l}\text { "Mergulho é uma atividade que faço desde pequeno, meu pai é } \\
\text { pescador e desde pequeno que ele mergulha e eu fui gostando } \\
\text { do mergulho e fui fazendo curso. Mergulho para mim é tudo. O } \\
\text { melhor trabalho que tem é o mergulho" (Luiz, } 31 \text { anos). }\end{array}$ \\
\hline Mergulho como esporte & $\begin{array}{l}\text { "Além de ser um esporte; é também uma profissão. Fazer } \\
\text { mergulho com pessoas é gratificante. Além de ser uma } \\
\text { profissão é um esporte fantástico" (Dinarte, } 28 \text { anos); } \\
\text { "O mergulho em si é um esporte muito bom. É o melhor que tem } \\
\text { desses que envolve natação; porque mexe com todo nosso } \\
\text { corpo. Serve de aprendizado para muitas pessoas, porque lida } \\
\text { com vidas" (Sergei, } 37 \text { anos). }\end{array}$ \\
\hline $\begin{array}{l}\text { Mergulho como fonte de } \\
\text { conhecimento }\end{array}$ & $\begin{array}{l}\text { "Significa conhecimento [...] conhecimento da área, sem contar } \\
\text { com o prazer de mergulhar" (Inácio, } 23 \text { anos). }\end{array}$ \\
\hline Mergulho como terapia & $\begin{array}{l}\text { "Explorar outro ambiente, sentir outra sensação" (Marcos, } 27 \\
\text { anos); } \\
\text { "É uma viagem. Quando eu mergulho, eu esqueço os problemas } \\
\text { que tenho na superfície" (Bira, } 37 \text { anos); } \\
\text { Eu acho que o mergulho é uma viagem em outro planeta dentro } \\
\text { de nosso planeta" (Maria, } 42 \text { anos); } \\
\text { "Mergulhar é um estado de espírito [...] O mergulho vai dar uma } \\
\text { sensação de bem-estar, ou talvez não, para cada pessoa [...] } \\
\text { Todo mundo é igual embaixo d'água [...] A melhor terapia é você } \\
\text { estar embaixo d'água [...] O autoconhecimento é gigantesco [...] } \\
\text { Vai muito além do esporte, é uma coisa psíquica mesmo [...] É } \\
\text { um bem-estar, é um autoconhecimento" (Domingos, } 45 \text { anos). }\end{array}$ \\
\hline $\begin{array}{l}\text { Mergulho como } \\
\text { significado ecológico }\end{array}$ & $\begin{array}{l}\text { "A conscientização, a preservação ambiental porque são seres } \\
\text { vivos (corais, a fauna e flora marítima) e para quem tem contato } \\
\text { com a natureza é riquíssimo e com a preservação ambiental as } \\
\text { futuras gerações poder desfrutar tudo o que a gente está } \\
\text { desfrutando hoje com a conscientização (Moura, } 29 \text { anos). }\end{array}$ \\
\hline
\end{tabular}

Fonte: Autores, 2017. Source: Authors, 2017.

Constatou-se, através dos relatos, que o mergulho proporciona novas sensações através da revelação do universo aquático, com diferentes cores, formas, texturas e criaturas. Uma experiencia que se deslumbra aos olhos dos profissionais de mergulho, gerando sentimento de liberdade, autoconhecimento e transformação. Eles reverenciam o mergulho como oportunidade única de despertar no turista/visitante uma conexão mais profunda com a natureza marinha. 


\title{
Ambiente ideal para a prática de mergulho na percepção dos entrevistados
}

A observação de peixes, geralmente, ocorre pela flutuação ou mergulho, com ou sem o uso de equipamentos especiais. Além de seu reconhecido papel nos ecossistemas aquáticos, os peixes têm forte apelo estético para atração de visitantes e reforçam o espetáculo de ambientes aquáticos privilegiados por ampliar o contato das pessoas com a ictiofauna de uma região (MTur, 2008).

Quando questionados sobre o ambiente ideal para a prática de mergulho, a maioria dos entrevistados destacou aspectos físicos da profundidade, elementos estéticos da variedade de espécies e a tranquilidade do mar como relevantes à prática adequada.

\begin{abstract}
"Depende muito (do perfil do mergulhador), para as pessoas que são credenciadas, que tem curso de mergulho. Tem mergulho em naufrágio, em caverna. No nosso caso aqui é um mergulho mais com iniciantes, pessoas que não sabem nadar, que não tem contato com equipamento. Então depende muito da qualificação de quem está indo mergulhar" (Dinarte, 28 anos).
\end{abstract}

Um dos entrevistados, afirma que a experiência de mergulhar "está acima de qualquer imaginário de mergulho ideal".

"Não existe ambiente ideal, no meu ponto de vista. O fato de estar embaixo d'água é uma experiência" (Domingos, 45 anos).

A percepção de mergulhadores sobre aspectos físicos, estéticos e de segurança pode ser notada a partir dos depoimentos do Quadro 2:

Quadro 2: Percepção sobre elementos físicos, estéticos e de segurança, RN/2017.

Table 2: Perception about physical, aesthetic and safety elements, RN/Brazil, 2017.

\begin{tabular}{|l|l|}
\hline Elementos físicos & $\begin{array}{l}\text { "Uma profundidade de } 10 \text { metros, sem correnteza, com uma } \\
\text { visibilidade ótima, cheio de peixes, um recife de coral saudável" } \\
\text { (Maria, 42 anos); } \\
\text { "A gente enfatiza muito a visibilidade" acrescenta (Rodolfo, } 27 \\
\text { anos); } \\
\text { "[...] Boa profundidade e pouca correnteza; é uma área excelente } \\
\text { para fazer mergulho" (Sergei, 37 anos); } \\
\text { "Um solo mais duro com corais" (Marcos, 27 anos). }\end{array}$ \\
\hline Elementos estéticos & $\begin{array}{l}\text { "Onde tem o recife de corais, tem mais peixes, cardumes de de } \\
\text { peixes, vários tipos de corais também como coral de fogo-que são } \\
\text { muito bonitos" (Luiz, 31 anos). }\end{array}$ \\
\hline Segurança & $\begin{array}{l}\text { "Quando o mar está calmo, temos menos pessoas para fazer o } 0 \\
\text { mergulho; o que fica menos perigoso" (Bira, 37 anos). }\end{array}$ \\
\hline
\end{tabular}

Fonte: Autores, 2017. Source: Authors, 2017 


\section{Impactos do mergulho sobre o ecossistema na percepção dos entrevistados}

Estudo com mergulhadores recreativos no Rio de Janeiro notou que relatos de tocar mais nos recifes de corais eram mais frequentes entre mergulhadores sem qualificação, em comparação aos que tinha uma ou mais qualificações para o mergulho (BROTTO et al., 2012).

Sobre a percepção de ocorrer ou não impacto do mergulho no meio ambiente, os mergulhadores demonstraram opiniões unânimes. A maioria (7) acredita que ocorram impactos negativos (7) em todo tipo de mergulho, porém alguns acreditam que o principal impacto seja decorrente do mergulho de snorkel, com nadadeiras. Segundo eles, o snorkel é a principal causa dos impactos ocasionados ao ecossistema aquático, resultando em danos aos corais. Entretanto, observa-se que o uso de nadadeiras é permitido somente para mergulhadores certificados ou turistas/visitantes que estejam acompanhados com um instrutor.

"[...] Se você tem algum manuseio com o equipamento, se nada bem, eu acho que para fazer o mergulho com cilindro você consegue mergulhar tranquilamente sem gerar impacto ao ambiente" (Dinarte, 28 anos);

"É possível sim. A gente enfatiza muito não tocar em nada, em conchas, em corais" (Rodolfo, 27 anos);

"É possível mergulhar sem causar impacto. Porém no mergulho autônomo dá para evitar causar impacto, mas no mergulho de snorkel eu acho que causa danos" (Luiz, 31 anos);

"Tem várias funções que dependendo do movimento, podem gerar impactos ao meio ambiente sim. Pisar no coral, jogando lixo, trazendo as espécies do fundo do mar" (Sergei, 37 anos);

"No momento que a gente está embaixo d'água, já está gerando impacto [...] o próprio chumbo que você está levando (por isso ele é revestido para causar um impacto menor) causa um impacto, obviamente. No próprio comportamento do animal (Domingos, 45 anos).

É interessante observar que somente um dos entrevistados mencionou o óleo das embarcações que são descritos por Buckley e Uvinha (2011) como causadora de impactos, assim como a mera presença do mergulhador na água, que pode provocar o estresse dos animais.

"Se seguissem as regras da natureza... sem protetor solar, sem nadadeira... seria possível não causar impacto, também tem o óleo das embarcações que causa impacto" (Bira, 37 anos). 


\section{Modificações recentemente percebidas no ecossistema marinho}

Sobre a percepção de alterações no ecossistema marinho nos últimos anos, os mergulhadores relataram o desaparecimento de diversas espécies, branqueamento e morte de corais como principais alterações no ecossistema marinho (Quadro 3).

Quadro 3: Percepção de alterações nos ambientes marinhos, RN/2017.

Table 3: Perception of changes in marine environments, RN/Brazil, 2017.

\begin{tabular}{|c|c|}
\hline $\begin{array}{l}\text { Desaparecimento } \\
\text { gradativo de espécies }\end{array}$ & $\begin{array}{l}\text { "Os mergulhadores percebem o desaparecimento de espécies } \\
\text { que responsabilizam o fato ao descuido de muitos. Antes não } \\
\text { era tão preservado como hoje" (Moura, } 29 \text { anos); } \\
\text { "Muitos peixes têm sumido, os corais têm morrido" (Marcos, } 27 \\
\text { anos); } \\
\text { "Lá na área que a gente mergulha tem vários corais } \\
\text { quebrados, muito sedimento nos corais" (Luiz, } 31 \text { anos); } \\
\text { "Percebi a falta de algumas espécies que a gente via } \\
\text { constantemente e os corais hoje tem uma coloração um pouco } \\
\text { menos chamativa, antes tinha uns corais mais coloridos. Tem } \\
\text { muitos corais mortos. Alguns corais encontram-se meio } \\
\text { branqueados, devido ao clima também e devido ao protetor } \\
\text { solar que o pessoal usa na área do mergulho" (Dinarte, } 28 \\
\text { anos); } \\
\text { "Antigamente a área era bem rica em vida marinha, aí depois } \\
\text { começou a mudar" (Rodolfo, } 27 \text { anos); } \\
\text { "Sim, percebi mudança, diferença na fauna, nos animais, } \\
\text { mudança nos peixes". Incrementou uma qualidade de peixes e } \\
\text { diminui a variedade. E eu percebo a mudança, os corais que } \\
\text { estão mais doentes, mais esbranquiçados (Maria, } 42 \text { anos). }\end{array}$ \\
\hline $\begin{array}{l}\text { Impacto causado pelas } \\
\text { pequenas embarcações }\end{array}$ & $\begin{array}{l}\text { "Pelo mergulho autônomo como é aqui, uma área bem rasa, } \\
\text { não! Mas pelo barulho dos barcos, interfere alguma coisa com } \\
\text { os peixes. Afasta algumas espécies" (Inácio, } 23 \text { anos). }\end{array}$ \\
\hline $\begin{array}{l}\text { Impacto perceptível sobre } \\
\text { as espécies }\end{array}$ & $\begin{array}{l}\text { "Quando mergulho, eu presto muita atenção no meio } \\
\text { ambiente. Porque como eu mergulho sempre nos mesmos } \\
\text { locais, eu vejo a diferença a cada dia daqueles locais" } \\
\text { (Domingos, } 46 \text { anos). }\end{array}$ \\
\hline
\end{tabular}

Fonte: Autores, 2017. Source: Authors, 2017.

Todas as atividades realizadas de forma inadequada acarretam alterações marcantes e redução drástica da biodiversidade marinha, produz modificação nas cadeias tróficas e mudanças na estrutura e funções das espécies aquáticas, com modificações diretas e indiretas, tornando algumas espécies ameaçadas de extinção (CORREIA; SOVIERZOSKI, 2005). Nesse sentido, merecem destaque os projetos de conservação para cavalosmarinhos, vulneráveis de extinção, e as piscinas naturais presentes em todo o país (MTur, 2008). 


\section{Alterações nos sistemas aquáticos atribuídas à atividade humana}

Quando indagados se as alterações percebidas estavam relacionadas com a atividade humana, todos os depoentes afirmaram que a contínua interferência do homem nos sistemas aquáticos produzem impactos negativos. A pesca predatória e o descarte de lixo acarretam as modificações percebidas, conforme os depoimentos:

"A pesca predatória é uma das principais causas" (Marcos, 27 anos);

"O próprio lixo que acabam jogando sem querer. Isso interfere bastante" (Edson, 28 anos);

"Tem um impacto humano, sim. Mas também eu acredito que o mar tem uma diferença de temperatura que pode chegar a isso. Um chute no coral de fogo, e a própria presença humana que assusta alguns peixes" (Maria, 42 anos);

\section{Capacitação de mergulhadores em Educação Ambiental marinha}

O toque no fundo do oceano constitui-se uma das atitudes que mais gera impacto para a vida subaquática e parece que o hábito está relacionado com a formação do mergulhador. Em estudo feito com mergulhadores no Rio de Janeiro constatou-se que quem possuía uma ou nenhuma qualificação, tocava mais o fundo com relação a quem possuía uma ou mais qualificações (BROTTO et al., 2012).

Quadro 4: Formação de mergulhadores sobre Educação Ambiental, RN/2017.

Table 4: Divers formation on environmental education, RN/Brazil, 2017.

\begin{tabular}{|c|c|}
\hline $\begin{array}{l}\text { Formação/Conheci- } \\
\text { mento em Educa- } \\
\text { ção Ambiental }\end{array}$ & Mergulhador \\
\hline $\begin{array}{l}\text { Tem formação } \\
\text { básica de mergulho }\end{array}$ & $\begin{array}{l}\text { "Não! Só os cursos de mergulho mesmo" (Inácio, } 23 \text { anos); } \\
\text { "Tivemos palestras e cursos com certificados" (Moura, } 29 \text { anos). }\end{array}$ \\
\hline $\begin{array}{l}\text { Formação com } \\
\text { Educação } \\
\text { Ambiental }\end{array}$ & $\begin{array}{l}\text { "Sim! Passamos. Os cursos que a gente fez sempre vem ensinando } \\
\text { a respeitar a natureza, a preservar" (Rodolfo, } 27 \text { anos); } \\
\text { "Passei pelo treinamento dado aqui há uns } 8 \text { anos atrás pelo ldema } \\
\text { quando veio formar agentes ambientais. Eles deram curso básico, } \\
\text { curso de preservação (condutas conscientes em ambientes recifais) } \\
\text { e eu participei deste curso. De lá para cá nunca mais teve } \\
\text { treinamento porque os recursos aqui estão meio complicados" } \\
\text { (Dinarte, } 28 \text { anos); } \\
\text { "Tenho um curso básico de mergulho e passei por vários cursos pelo } \\
\text { SENAC, pelo Idema. Cursos de atendimento, de meio ambiente, de } \\
\text { tudo... Carteira de marinheiro, curso de orientador turístico local" } \\
\text { (Sergei, } 37 \text { anos). }\end{array}$ \\
\hline $\begin{array}{l}\text { Cursos de tempos } \\
\text { remotos }\end{array}$ & $\begin{array}{l}\text { "Cursos de mergulho básico e avançado já. Fiz um curso... Já faz } \\
\text { algum tempo... A gente fez alguns cursos relacionados à área de } \\
\text { mergulho" (Marcos, } 27 \text { anos). }\end{array}$ \\
\hline $\begin{array}{l}\text { Instrução/conheci- } \\
\text { mento de primeiros } \\
\text { socorros }\end{array}$ & $\begin{array}{l}\text { "Eu sou instrutora de mergulho com cilindro. Tenho mais de } 15 \\
\text { cursos. Eu tenho curso básico, avançado, resgate instrutor, primeiros } \\
\text { socorros" (Maria, } 42 \text { anos). }\end{array}$ \\
\hline $\begin{array}{l}\text { Aprendizado pela } \\
\text { experiência }\end{array}$ & $\begin{array}{l}\text { "O único treinamento quem me deu foi a própria natureza. Eu fiz um } \\
\text { curso de oceanografia na USP" (Domingos, } 45 \text { anos). }\end{array}$ \\
\hline
\end{tabular}

Fonte: Autores, 2017. Source: Authors, 2017. 
Em relação à implantação de cursos na área de Educação Ambiental, os entrevistados concordaram sobre a importância desse conhecimento para a formação e certificação de mergulhador. Eles reportaram que as operadoras de cursos de mergulho precisam aprimorar as novas demandas de caráter ambiental, adquirindo domínio sobre a temática da sustentabilidade, conservação e preservação dos ecossistemas marinhos.

A Educação Ambiental é um instrumento que abre possibilidades de construção de novos saberes. A proposta metodológica de Educação Ambiental Marinha deve difundir o conhecimento sobre o ambiente marinho e a adoção de práticas ecologicamente corretas, promovendo medidas básicas para o incentivo do uso sustentável dos recursos naturais.

Quando questionados sobre a Educação Ambiental, transmissão de conhecimento, antes da prática de mergulho para turistas a respeito dos cuidados que se deve ter em relação ao descarte de lixo, evitar tocar o fundo do oceano entre outros, obteve-se:

"Dependendo da ocasião sim. Evitando ter contato, porque o dano vem a curto e longo prazo, evitar sujar o local" (Marcos, 27 anos);

"Transmito. A gente fala principalmente de não pisar no coral e sobre o uso de nadadeira que não pode. E também avisamos para não jogar lixo no mar" (Luiz, 31 anos);

"Falo sobre preservação ambiental, conscientizamos o turista sobre as belezas que tem na área para eles abrirem os olhos a esse outro mundo que existe embaixo da água, cheio de vida. Eu acho que a experiência geral... Andar de barco, conhecer o fundo marinho, as espécies marinhas e ser conscientizado sobre a preservação ambiental... Acho que isso enriquece a vida das pessoas" (Maria, 42 anos);

"O IDEMA tem um plano de manejo... Então existe um cuidado devido à preservação, para estudar como é que está... Se precisa diminuir o número de pessoas ou se precisa retirar algo. Em alguns planos de manejo foram retiradas nadadeiras, a âncora não pode jogar na água... E a quantidade de pessoas para a prática de mergulho é limitada" (Sergei, 37 anos);

"Aqui mesmo no meu trabalho transmito em preleções. Eu faço a preleção para o pessoal que está indo mergulhar. A gente os conscientiza para que não pisem nos corais, não joguem lixo no mar" (Dinarte, 28 anos);

"Falamos sobre o uso do equipamento... Pedimos para eles preservarem, não tirar nada do mar, não pisar nos corais" (Rodolfo, 27 anos). 


\section{Conhecimento de restrições e cuidados prévios à prática do mergulho}

O objetivo deste tópico é demonstrar o conhecimento de mergulhadores em relação às restrições impostas pelo órgão gestor para a prática do mergulho. De acordo com o quadro abaixo, observa-se que a maioria dos mergulhadores desconhece regras ou critérios para orientações antes e durante a prática do mergulho.

Quadro 5: Conhecimento, restrições e regras/recomendações estabelecidas dos mergulhadores para mergulho, RN/2017.

Table 5: Knowledge, restrictions and rules/recommendations laid downs by divers for scuba diving, RN/Brazil, 2017.

\begin{tabular}{|c|c|}
\hline Problema prévio de saúde & $\begin{array}{l}\text { "A gente sempre pergunta se o pessoal tem algum } \\
\text { problema de saúde. Se fez alguma cirurgia recente. } \\
\text { Fazemos uma recomendação para que eles não } \\
\text { mergulhem. Gestantes também" (Rodolfo, } 27 \text { anos) }\end{array}$ \\
\hline $\begin{array}{l}\text { Restrições do uso de } \\
\text { nadadeiras }\end{array}$ & $\begin{array}{l}\text { "Pessoas que não tem credencial não podem usar } \\
\text { nadadeira" (Moura, } 29 \text { anos). }\end{array}$ \\
\hline $\begin{array}{l}\text { Restrições para não tocar } \\
\text { e ou pisar }\end{array}$ & $\begin{array}{l}\text { "Não pode tocar em nada, não pode jogar lixo no mar, } \\
\text { não pode pisar no coral" (Maria, } 42 \text { anos). }\end{array}$ \\
\hline $\begin{array}{l}\text { Desconhece } \\
\text { restrições/cuidados } \\
\text { adotados }\end{array}$ & $\begin{array}{l}\text { "Aqui não. Em Maracajaú nunca vi" (Inácio, } 23 \text { anos). } \\
\text { "Não. Aonde eu pratico não. Não tem nenhuma regra que } \\
\text { restringe essa atividade" (Domingos, } 45 \text { anos) }\end{array}$ \\
\hline
\end{tabular}

Fonte: Autores, 2017.Source: Authors, 2017.

Segundo os depoimentos, o uso de nadadeiras por iniciantes pode deixar a água turva, perturbando os peixes, mas a principal causa da proibição das nadadeiras pelo Idema é o choque físico com os corais. Não foi encontrado estudo que comprove se o uso de nadadeiras em ambientes de recifes de corais causa degradação, entretanto boa parte dos entrevistados alertou a restrição em relação ao uso de nadadeiras, apontando-as como uma das principais causas da quebra dos corais em Maracajaú.

\section{Mergulho recreativo como atrativo turístico}

O turismo, atualmente, é uma das atividades mais importantes para o desenvolvimento econômico. Contudo, tratando-se de turismo em áreas naturais, tanto o turismo subaquático, quanto a prática de mergulho prescindem de educação ambiental. Torna-se oportuna uma agenda que promova a sensibilização em relação à vida marinha e alerte sobre os possíveis impactos da interação humana com o ecossistema. De acordo com o Ministério do Turismo (2013), o turismo em áreas naturais é o segundo maior motivo de busca pelos turistas internacionais e o mergulho está entre as atividades mais procuradas. Os entrevistados destacaram a importância do turismo subaquático para o desenvolvimento do destino turístico, conforme quadro abaixo: 
Quadro 6: Percepção de mergulhadores sobre turismo subaquático, RN/2017.

Table 6: Perception of divers on underwater tourism, RN, Brazil/2017.

\begin{tabular}{|l|l|}
\hline $\begin{array}{l}\text { Percepção dos } \\
\text { entrevistados } \\
\text { referente ao turismo } \\
\text { subaquático }\end{array}$ & "O turista que vem aqui traz benefícios... Renda pra Maracajaú \\
& "Com certeza. Tem alguns lugares, inclusive no Caribe, que \\
& vivem de mergulho. Tem algumas ilhas (Aruba, Bonete, Curaçao, \\
& Grécia, Noronha) que sobrevivem de mergulho. É uma rede, é um \\
& motor que gira em torno disso. Tem uma cidade aqui no \\
& Nordeste, Arraial do Cabo, que a economia gira em torno do \\
& mergulho, passeios náuticos e etc. Aqui a gente ainda não tem \\
& essa mentalidade" (Domingos, 45 anos).
\end{tabular}

Fonte: Autores, 2017. Source: Authors, 2017.

\section{Medidas para evitar os impactos negativos do turismo subaquático}

A importância de se estabelecer limites para respeitar a capacidade de carga e a redução do número de turistas/mergulhadores irá facilitar a supervisão durante a prática de mergulho e são medidas necessárias para evitar impactos negativos. Aspectos práticos sobre o local de descarte do lixo e legibilidade insuficiente (sinalizações e ou placas) constavam dos relatos:

"Ter uma lixeira em todo lugar, ter mais placas explicando que aqui é uma área de proteção ambiental, uma APA (Maria, 42 anos);

"O turista antes de embarcar passa primeiro por uma preleção, ver algumas fotos, vídeos... E como os corais são frágeis; como eles devem ser tratados, porque as vezes o pessoal embarca aqui e já vai direto para o mar, tem todo aquele tumulto e as pessoas não absorvem essa informação perfeitamente" (Dinarte, 28 anos);

"Conscientizar a galera para não pisar no coral" (Luiz, 31 anos);

"A política da empresa tem regras e que se não forem cumpridas, eles recebem notificações. $O$ número de pessoas não pode passar desse limite" (Moura, 29 anos);

"Primeiro, qualificar realmente as pessoas e não dar esses cursos técnicos básicos que as pessoas acham que sabem de tudo. Maior qualificação. Falta muita, não só no turismo" (Domingos, 45 anos).

\section{Evolução do turismo subaquático na percepção de mergulhadores}

Em prospecção imaginária sobre o futuro do turismo subaquático e da prática de mergulhos, observa-se a preocupação nos depoimentos dos mergulhadores entrevistados. Nem todos estão com expectativas de melhoras em relação ao futuro como retratado nos depoimentos a seguir: 
"De acordo com o que vem acontecendo eu acho que não vai ser tão boa a qualidade" (Marcos, 27 anos);

"Se continuar sem uma Educação Ambiental, a situação estará precária" (Bira, 37 anos);

"Eu creio que ainda vai mudar muito pra pior, porque o que causa impacto aqui hoje no mergulho é o próprio turismo. Pela questão da falta de conscientização" (Dinarte, 28 anos).

Segundo Pedrini et al., (2010), o turismo marinho brasileiro tem sido altamente prejudicial. O mesmo afirma que já se tem uma forte noção de que a poluição e a degradação causadas pelos seres humanos geram impactos negativos ao mar. Ele conclui que para evitar danos aflorantes de curto e longo prazo, o mergulho recreativo deve ser controlado sob a perspectiva do turismo ecológico sustentável.

\section{Percepção de mergulhadores sobre o futuro dos oceanos}

Este tópico concentra relatos de percepção dos entrevistados em relação ao que pensam sobre o futuro dos oceanos. Notou-se que a maioria das respostas tinha conteúdo pessimista, sem perspectiva do que está por vir. Apenas uma resposta contendo previsão positiva a respeito do futuro dos oceanos.

"Do jeito que as coisas estão indo eu acho que vai chegar um tempo que algumas espécies vão desaparecer, até os próprios corais não vão ser mais os mesmos" (Dinarte, 28 anos);

"Meu desejo que continue melhorando e crescendo. Eu sei que não é a realidade. Está tendo muita caça a animais e peixes. Se o mar continuar esquentando ele vai morrer" (Maria, 42 anos);

"Cada vez tem mais mergulhadores no mundo, eu acho que não vai parar de crescer. E esse crescimento junto com uma conscientização, eu acho que pode ser até bom, se realmente as pessoas fazem por amor e com cuidado do que estão fazendo. Eu acho que o mergulho pode ser uma atividade que ajude as pessoas a amar o oceano" (Maria, 42 anos);

Encontrou-se apenas uma resposta com teor realista, sugerindo medidas para mitigar danos sobre o oceano:

"É importante manter uma preservação mais severa lá. Por exemplo, lá não pode pescar... Então deve ter fiscalização" (Rodolfo, 27 anos). 
No que se refere ao controle do fluxo de turistas, a capacidade de carga em mergulhos recreativos, pode ser definida como a quantidade de pessoas que uma determinada área pode suportar em um determinado tempo, sem que haja prejuízos ao meio natural do local (CIFUENTES, 1992), a exemplo do depoimento abaixo:

"Do jeito que vai aí, eu acho que pode diminuir o número de corais... Lá tem bastante coral quebrado, mais por causa do snorkel. O mergulho com cilindro dá para desenrolar ainda, porque a gente vai sempre acompanhado do pessoal. Mas quando chega 200 pessoas no mesmo local, em breve; vai ter menos quantidade de coral por lá" (Luiz, 31 anos).

Atualmente, o Índice de Saúde do Oceano (OHI, sigla em Inglês) é extremamente crítico em relação ao fornecimento de alimentos, aproveitamento dos produtos naturais e as possibilidades de turismo dos mares. $\mathrm{E}$ com $\mathrm{o}$ aquecimento do planeta, há diversas mudanças biogeoquímicas desencadeadas pelo aumento das emissões de gases do efeito estufa que afetam a biodiversidade marinha e consequentemente os seres humanos (GIRADI, 2013).

\title{
Demandas urgentes para o futuro do turismo subaquático
}

Quando os mergulhadores foram questionados sobre sugestão de melhorias para o turismo nos oceanos e a prática de mergulho foram obtidas as seguintes respostas:

\begin{abstract}
"Os turistas deveriam ser mais conscientes. Se todo mundo usar a consciência que está indo para uma APA só vai melhorar. Mas para isso, o órgão que controla o local de mergulho e faz a fiscalização, tem que conscientizar as pessoas que vem aqui" (Dinarte, 28 anos);

"O cliente chega aqui e chega muito mal informado da área de mergulho" (Sergei, 37 anos).
\end{abstract}

O fornecimento de instruções necessárias no momento da venda do passeio é de responsabilidade das operadoras de turismo, principalmente quando se trata de uma área de proteção ambiental (APA).

De acordo com as respostas obtidas, os mergulhadores fazem as chamadas "preleções", ou seja, informam aos turistas (que fazem ou não o mergulho) o que pode e o que não pode ser feito durante a prática de mergulho. Entretanto, nem todos os turistas/visitantes respeitam as recomendações.

"Mais a questão da preservação. Apesar da gente enfatizar muito em não pisar nos corais, sempre tem alguém que faz isso" (Rodolfo, 27 anos). 
Durante as entrevistas observou-se a preocupação dos mergulhadores referente aos cursos de capacitação e qualificação.

\begin{abstract}
"Sim, eu acredito que todas as pessoas que trabalham como profissionais na área de mergulho têm que ter no mínimo uma carteira de dive master" (Maria, 42 anos);

"Com relação ao mergulho eu acho que falta qualificar mais os instrutores. Aí teria mais qualidade no serviço e consequentemente teria menos impacto na área" (Marcos, 27 anos).
\end{abstract}

No plano de manejo da APA dos Recife de Corais estão previstas ações socioambientais, além de quatro tópicos de planejamento e gestão do turismo, são eles: Visitação e Desenvolvimento do Turismo; Monitoramento da Visitação Turística; Turismo Subaquático e Estudos de Capacidade de Carga; e Monitoramento do Turismo Subaquático. No entanto, não há indícios da implementação dos mesmos.

Uma das questões levantadas pelos entrevistados que são prejudiciais ao oceano é o uso de protetor solar.

"Eu acho que seria uma ideia os donos das operadoras... Proibir o uso do protetor solar, porque um dos fatores que prejudica os corais é o protetor" (Bira, 37 anos).

De fato, Downs et al. (2016) provou que a oxibenzona, substância encontrada em protetores solares, induz o branqueamento de corais, também causa alterações em peixes e mamíferos. Segundo o autor, algumas modificações são necessárias para mitigar os danos causados ao meio ambiente como: a) proibir o uso de produtos que contenham componentes perigosos em áreas onde os recifes de corais sejam mais susceptíveis à exposição; b) campanha de políticas públicas em áreas de manejo de recifes de corais que informe aos visitantes e habitantes locais sobre o impacto ambiental da poluição por protetor solar e pedi-los que usem produtos de proteção solar sem componentes perigosos; c) convencer as pessoas a reduzir a quantidade de protetor solar. Aplicar a loção apenas no pescoço, rosto, pés e costas das mãos pode reduzir a quantidade de protetor solar que vai para a água em $90 \%$; utilizar roupas com proteção solar desenvolvidas para reduzir a exposição aos raios ultravioleta/UV. Por último, Downs (2018) faz um apelo para que os consumidores exijam inovações dos fabricantes com relação à formulação de seus produtos. Se essas atitudes fossem tomadas, os danos ao ecossistema seriam reduzidos consideravelmente. 


\section{Considerações Finais}

Os mergulhadores autônomos de Maracajaú e Natal têm uma boa percepção sobre os efeitos do turismo no meio aquático. Percebem que o mar precisa ser conservado, apesar da sua importância para o turismo. Acreditam que o grande fluxo de turistas pode prejudicar o ecossistema marinho.

Conclui-se, com base na percepção dos mergulhadores, que ocorre uma lacuna na responsabilidade do IDEMA de comunicar/assinalar à população que o local trata-se de uma APA. Dessa forma, urge a demanda por ações de Educação Ambiental e que monitorem o impacto turístico. Fazer cumprir os limites da capacidade de carga estabelecidos no plano de manejo, controlando a frequência de mergulhadores autônomos (de snorkel ou com cilindro) para preservar os recifes de corais, o cavalo marinho, entre outros.

É premente o planejamento turístico para prática adequada do turismo marinho na área costeira potiguar, envolvendo Política Pública Estadual, com ações de Educação Ambiental direcionadas à comunidade local, aos mergulhadores, aos visitantes e aos turistas usuários de passeio de barco. Investimentos na Unidade de Conservação para que as mesmas possam instrumentalizar o turismo aquático de modo sustentável na região.

\section{Referências}

AUGUSTOWSKI, M.; FRANCINE JR., R., O mergulho recreacional como ferramenta para o turismo sustentável em unidades de conservação marinhas. In: CONGRESSO BRASILEIRO DE UNIDADES DE CONSERVAÇÃO, 3., 2002, Fortaleza. Anais..., Fortaleza: Rede ProUC, p. 443-52, 2002.

BARDIN, L. Análise de conteúdo. Lisboa: Ed. 70, 1979.

BROTTO, D.S.; PEDRINI, A.G.; BANDEIRA, R.R.C.; ZEE, D.M.W. Percepção ambiental do mergulhador recreativo no Município do Rio de Janeiro e adjacências: subsídios para a sustentabilidade do ecoturismo marinho. Revista Brasileira de Ecoturismo, São Paulo, v.5, n.2, p.297-314, 2012.

BUCKLEY, R; UVINHA, R.R. Turismo de Aventura: Gestão e Atuação Profissional. Rio de Janeiro: Campus, 2011.

BUENO, C; PARDO, F. L.; REIFF, F.; VINHA, V. D. Ecoturismo responsável e seus fundamentos. Rio de Janeiro: Technical Books, 2011, $256 \mathrm{p}$.

CIFUENTES, M. Determinación de capacidade de carga turística en áreas protegidas. Turrialba, Costa Rica: Centro Agronómico Tropical de Investigación y Enseñanza/CATIE, 1992.

CORREIA, M. D.; SOVIERZOSKI, H. H. Ecossistemas Marinhos: recifes, praias e manguezais. Maceió: Edufal, 2005. 
CHAUÍ, M. Convite à Filosofia. São Paulo: Ática, 2000.

DAVIDOFF, L. Introdução à psicologia. São Paulo: McGraw-Hill, 1983.

DOWNS, C.A., KRAMARSKY-WINTER, E., SEGAL, R. et al. Arch Environ Contam Toxicol. Archives of Environmental Contamination and Toxicology. Nova York: v. 70, n. 2, p 265-88, 2016.

DOWNS, C. Poluição por protetor solar. Uma ameaça aos corais séria e cada vez mais evidente. Campinas: Divers Alert Network/DAN Brasil, 2018.

GIRADI, G. Crise Atual e futura dos oceanos. O Estadão de São Paulo, São Paulo. 2013.

HALLS, M.; KRESTOVNIKOFF, M. Scuba diving (Eyewitness Companion). Reino Unido: Dorling Kindersley, 2006.

MARK, J.J. Ten Noble and Notorious Women of Ancient Greece. United States/United Kingdom: Ancient History Encyclopedia, 2014.

MORRIS, C. G.; MAISTON, A. A. Introdução à Psicologia. São Paulo: Prentice-Hall, 2004.

MUSA, G.; DIMMOCK, K. Scuba diving tourism: Introduction to special issue. Tourism in Marine Environments: Special Issue, London, v. 8, n.1/2, p. 15, 2012.

MTur, MINISTÉRIO DO TURISMO. Ecoturismo: Orientações básicas. Brasília: Ministério do Turismo, 2008.

NEIMAN, Z.; SARACENI, R. F.; GEERDINK, S. Levantamento qualiquantitativo da produção científica sobre Ecoturismo no Brasil. Revista Brasileira de Ecoturismo, São Paulo, v. 3, n. 3, 2010.

PEDRINI, A. G.; MESSAS, T.P.; PEREIRA, E.S.; GHILARDI-LOPES, N.P.; BERCHEZ, F.A. Educação Ambiental pelo ecoturismo numa trilha marinha no Parque Estadual da llha Anchieta, Ubatuba (SP). Revista Brasileira de Ecoturismo, São Paulo, v. 3, n. 3, p. 428-459, 2010.

PEDRINI, A. G.; BROTTO, D. S.; LOPES, M. C.; MESSAS, T. Gestão de Áreas Protegidas com Educação Ambiental Emancipatória pelo Ecoturismo Marinho: A proposta do Projeto Ecoturismar/OLAM. Ciência e Tecnologia, Rio Claro (SP): n.3, p. 6-81, 2011.

QUEIROZ-NETO, A.C. Dive tourism - Um mergulho conceitual. In: SEMINARIO DE PESQUISA EM TURISMO DO MERCOSUL, 7. Turismo e Paisagem: Relação Complexa. Anais..., Caxias do Sul: Universidade Caxias do Sul, p. 1-15, 2012.

ROBBINS, S. P. Comportamento Organizacional. São Paulo: PrenticeHall, 2002.

ROWE, R. Y. G.; SANTOS, G. E. O. Turismo de mergulho: análise do comportamento de viagens dos mergulhadores brasileiros. Caderno Virtual de Turismo, Rio de Janeiro, v.16, n.3, p. 61-75, dez. 2016. 
SILVA, I. B.; FUJI, M. T.; MARINHO-SORIANO, E. Influence of tourist activity on the diversity of seaweed from reefs in Maracajaú, Atlantic Ocean, Northeast Brazil. Rev. Revista Brasileira de Farmacognosia. v. 22, n.4, p. 889-893 2012.

SILVA, J. N.; GHILARDI-LOPES, N. P. Indicators of the impacts of tourism on hard-bottom benthic communities of llha do Cardoso State Park (Cananéia) and Sonho Beach (Itanhaém), two southern coastal areas of São Paulo State (Brazil). Ocean \& coastal management, v. 58, p. 1-8, 2012.

Diego Vitor Filgueira-da-Silva: Universidade Federal do Rio Grande do Norte, Natal, RN, Brasil.

E-mail: diegofilgueira.1@hotmail.com

Link para o currículo Lattes: http://lattes.cnpq.br/9450545617988234

Ana Beatriz Gomes-Ferreira: Universidade Federal do Rio Grande do Norte, Natal, RN, Brasil.

E-mail: beatriz_biologia@hotmail.com

Link para o currículo Lattes: http://lattes.cnpq.br/3428643449624579

Sueli Aparecida Moreira: Universidade Federal do Rio Grande do Norte, Natal, RN, Brasil.

E-mail: suelimoreira@yahoo.com.br

Link para o currículo Lattes: http://lattes.cnpq.br/9469781068838287

Data de submissão: 03 de outubro de 2018

Data de recebimento de correções: 14 de dezembro de 2018

Data do aceite: 14 de dezembro de 2018

Avaliado anonimamente 